JAAKFE UNTAN

(Jurnal Audit dan Akuntansi Fakultas Ekonomi Universitas Tanjungpura)

Vol. 10 No. 1, Juni 2021

ISSN-P: (2252-7486), ISSN-E: (2746-6140)

https://jurnal.untan.ac.id/index.php/jaakfe

\title{
ANALISIS FISHBONE DIAGRAM UNTUK MENGEVALUASI PEMBUATAN PERALATAN ALUMINIUM STUDI KASUS PADA SP ALUMINIUM YOGYAKARTA
}

\author{
Novitasari Eviyanti ${ }^{1 * *}$ \\ ${ }^{1}$ Politeknik Negeri Semarang, Indonesia \\ *E-mail: eviyantinovitasari@gmail.com
}

\begin{abstract}
Abstrak
Penelitian ini dilakukan untuk membantu SP Aluminium menganalisis penyebab banyaknya produk cacat yang dihasilkan, sehingga meningkatkan banyaknya biaya produk cacat yang dikeluarkan oleh SP Aluminium untuk memperbaiki produk cacat tersebut, selain itu juga menyebabkan terbuangnya waktu dan tenaga sehingga SP Aluminium hanya dapat memenuhi $80 \%$ pesanan pelanggan. Sehingga perlu dievaluasi apa sajakah yang menyebabkan tingginya produk cacat yang dihasilkan. Penelitian ini menggunakan jenis penelitian kualitatif dengan model studi kasus di SP Aluminium Yogyakarta. Pengumpulan data yang dilakukan penulis adalah dengan terjun langsung ke lapangan, melihat, mengobservasi, mengumpulkan data primer dengan melakukan wawancara secara langsung kepada narasumber. Peyebab banyaknya produk cacat yang dihasilkan berasal dari beberapa factor seperti penggunaan peralatan produksi yang masih tradisional, kurangnya memilih sumber daya yang kompeten, tidak adanya pelatihan yang terstruktur dan bahan baku alat cetak yang tidak bisa bertahan lama.
\end{abstract}

Kata kunci: Fishbone, Efisiensi, Produk Cacat dan SP Aluminium.

Article History: Received:05-05-2021 Revised:-

Accepted:04-06-2021 
Vol. 10, No. 1 (Juni 2021)

Novitasari Eviyanti

DOI: http://dx.doi.org/10.26418/jaakfe.v10i1.45233

Hal 10-18

\section{PENDAHULUAN}

SP ALUMINIUM merupakan salah satu UMKM di Yogyakarta yang bergerak di bidang pengecoran, pelebuan, pembuatan kerajinan souvenir dan peralatan rumah tangga yang berbahan dasar aluminium seperti wajan, panci, soblok, kendil dan aksesories, 90\% produksinya sudah tersebar di seluruh Indonesia melalui wholesale Lotte Mart, sedangkan yang 10\% diekspor ke beberapa negara di Asia Tenggara seperti Malaysia dan Thailand. Dalam hal ini, SP Aluminium hanya mampu memenuhi kira-kira $80 \%$ permintaan pasar. Tingginya permintaan pasar menuntut SP Aluminium dapat meningkatkan efisiensi dalam proses produksi pembuatan wajan. Namun dari data yang dihasilkan, SP Aluminium memiliki kendala dalam proses produksi, yaitu tingginya produk cacat yang dihasilkan setiap proses produksi berjalan. Selain permintaan konsumen tidak terpenuhi, banyaknya waktu dan biaya yang dikeluarkan untuk mengatasi produk cacat tersebut.

Dari hasil data yang didapat, dalam kurun waktu pehitungan produk cacat bulanan presentase produk cacat tersebut sebesar $24 \%$, hal tersebut membuat perusahaan mengeluarkan biaya lebih untuk memperbaiki atau mengerjakan kembali produk cacat tersebut. Meskipun produk cacat dapat diperbaiki kembali, namun biaya yang dikeluarkan cukup tinggi.

Tabel 1 Biaya Pengerjaan Kembali Poduk Cacat Tahun 2014 -2018

\begin{tabular}{|l|l|l|}
\hline Tahun & $\begin{array}{l}\text { Biaya Pengerjaan Kembali } \\
\text { (Rupiah) }\end{array}$ & Penjualan (Rupiah) \\
\hline 2014 & 2.410 .753 .224 & 19.275 .151 .617 \\
\hline 2015 & 2.450 .818 .722 & 20.951 .251 .757 \\
\hline 2016 & 2.920 .702 .255 & 22.528 .227 .696 \\
\hline 2017 & 3.390 .585 .788 & 24.105 .203 .635 \\
\hline 2018 & 3.831 .361 .940 & 25.551 .515 .853 \\
\hline
\end{tabular}

Sumber: Data Diolah, 2016.

Dari tabel 1.1 diatas menunjukan bahwa biaya yang digunakan untuk mengerjakan kembali produk cacat sangatlah tinggi menyebabkan tingginnya biaya produksi, sehingga dengan adanya penelitian ini diharapkan dapat meminimalisir biaya produk cacat sehingga bisa meningkatkan efisiensi produk.

Rumusan masalah dalam penelitian ini berfokus pada evaluasi proses produksi sehingga menemukan penyebab terjadinya produk cacat dengan diagram sebab akibat untuk meningkatkan kualitas dan meminimalisir biaya produksi pada SP Aluminium.

\section{LANDASAN TEORI}

\section{Pengertian Biaya Kualitas}

Menurut Supriyono (2002) biaya kualitas adalah biaya yang berhubungan dengan penciptaan, pengidentifikasian, perbaikan dan pencegahan kerusakan. Menurut Carter dan Usry (2006: 198) biaya kualitas adalah biaya yang tidak hanya untuk mencapai kualitas, tetapi juga biaya yang terjadi karena kualitas buruk. Hansen dan Mowen (2009: 272) mendefinisikan biaya kualitas (cost of quality) adalah biaya-biaya yang timbul karena mungkin atau telah terdapat produk yang kualitasnya buruk. Dari pengertian diatas dapat disimpulkan bahwa biaya kualitas 
Vol. 10, No. 1 (Juni 2021)

Novitasari Eviyanti

DOI: http://dx.doi.org/10.26418/jaakfe.v10i1.45233

Hal 10-18

merupakan biaya yang dikeluarkan sebelum produk jadi yang dimulai dari penciptaan, pengidentifikasian, perbaikan dan pencegahan kerusakan. Dengan adanya biaya kualitas diharapkan kerusakan dapat diidentifikasi sedini mungkin sehingga biaya yang dikeluarkan untuk perbaikan tidak terlalu banyak dengan metode pencegahan, penilaian, kegagalan internal dan eksternal.

\section{Distribusi Optimal Biaya Kualitas}

Menurut Supriyono (2002) dalam kegiatan pengendalian kualitas para manajer mempunyai tanggung jawab untuk menilai tingkat optimal dari kualitas dan manajer juga harus mampu menentukan jumlah relatif yang harus dikeluarkan untuk setiap kelompok tersebut. Menurut Supriyono (2002) terdapat dua pandangan mengenai biaya kualitas yang optimal.

\section{a. Pandangan tradisional}

Menurut para ahli kualitas menyatakan bahwa keseimbangan kualitas dapat diterima jika diasumsikan jika semakin tinggi biaya pencegahan dan penilaian maka biaya kegagalan akan menurun. Selama penurunan biaya kegagalan lebih besar dari kenaikan biaya pencegahan dan penilaian, maka perusahaan harus meningkatkan usahanya untuk meminimalisir unit-unit yang tidak sesuai titik capaian sehingga akan mencapai titik yang menunjukan keseimbangan antara peningatan biaya pencegahan dan biaya kegagalan jika ingin menciptakan produk yang berkualitas dengan biaya yang terjangkau.

\section{b. Pandangan kelas dunia (zero defect)}

Persaingan yang semakin kompetitif membuat industri manufaktur berlomba-lomba menciptakan produk yang memiliki daya saing yang berkualitas. Jika pandangan tradisional dinilai salah maka perusahaan yang mengetahui kesalahan ini akan memperbaiki dengan mengurangi produk rusak dan menurunkan biaya kualitas total mereka. Tingkat optimal biaya kualitas terjadi ketika tidak ada produk cacat.

Menurut Kaplan dan Atkinson (1998) banyak perusahaan mengeluarkan biaya kualitas berkisar antara 10\%-20\% dari pendapatan penjualan. Tolak ukur untuk menentukan bahwa pengelolaan biaya kualitas sudah terkendali adalah besar biaya kualitas pada masing-masing laporan kinerja biaya kualitas tidak melebihi anggaran dan 2.5\% dari penjualan aktual (Hansen dan Mowen, 2007).

\section{Analisis Sebab Akibat/ Fish Bone Diagram}

Diagram sebab akibat merupakan diagram yang dikembangkan oleh Dr. Kaory Ishikawa pada tahun 1943 yang digunakan untuk menunjukan hubungan sebab akibat dari suatu masalah atau penyimpangannya. Menurut Besterfield (2004) diagram sebab akibat atau fishbone diagram merupakan gabungan sebuah garis dan symbol yang menunjukan hubungan sebab dan akibat. Bagian ujung kanan dari diagram ini menunjukan akibat atau permasalahan yang terjadi, sedangkan garis atau cabang tulang ikannya menggambarkan penyebabnya yang dikategorikan ke dalam kelompok-kelompok seperti factor manusia, material, mesin, metode dan lingkungan. Liliana (2016) merangkum empat langkah penggunaan fishbone diagram: 
Vol. 10, No. 1 (Juni 2021)

Novitasari Eviyanti

DOI: http://dx.doi.org/10.26418/jaakfe.v10i1.45233

Hal 10-18

1. Identifikasi masalah

2. Mencari tahu factor-faktor utama yang terlibat

3. Mengidentifikasi kemungkinan penyebab

4. Menganalisis diagram

\section{METODE}

Penelitian ini merupakan penelitian studi kasus dengan model pendekatan studi kasus di SP Aluminium Yogyakarta. Menurut Yin (2014), secara umum studi kasus adalah strategi yang lebih cocok bila pokok pertanyaan suatu penelitian berkenaan dengan "how" atau "why" dan peneliti hanya memiliki sedikit peluang untuk mengontrol peristiwa-peristiwa yang akan diselidiki. Menurut Cooper dan Schindler (2006), riset kualitatif terdiri dari rangkaian teknik interpretasi yang akan menjelaskan, mentransformasikan, menerjemahkan, dan menjelaskan makna, bukan frekuensi, dari suatu kejadian dalam dunia sosial yang kurang lebih terjadi secara alami. Riset kualitatif bertujuan untuk mendapatkan pemahaman yang mendalam mengenai suatu situasi. Menurut Hennink (2011), riset kualitatif adalah pendekatan yang memperkenankan meneliti atau menguji pengalaman orang secara detail, dengan menggunakan sekumpulan spesifik metode riset seperti wawancara, focus group discussion, observasi, muatan analisis, metode visual, dan sejarah hidup atau biografi. Dari beberapa pengertian diatas, dapat dikatakan bahwa studi kasus menyelidiki, menjelaskan, dan mentransformasikan suatu peristiwa dengan mengetahui keadaan sebenarnya.

Pengumpulan data dilakukan dengan terjun langsung ke lapangan dengan melihat, mengobservasi, mengumpulkan data primer dengan melakukan wawancara secara langsung. Kemudian peneliti melakukan interpretasi data dengan mengidentifikasi proses produksi di SP Aluminium dan menghubungkan dengan komponen fishbone diagram.

\section{HASIL DAN PEMBAHASAN \\ Proses Produksi SP Aluminium Yogyakarta}

Berdasarkan hasil observasi yang dilakukan penulis, alur proses kegiatan produksi dimulai dengan beberapa proses.

\section{Peleburan}

Untuk bahan baku pebuatan peralatan aluminium menggunakan 80\% Aluminium batangan, sedangkan yang $20 \%$ menggunakan aluminium bekas yang dikumpulkan oleh pengepul. Seperti wajan bekas, panci bekas dan lain sebagainya. Peleburan menggunakan api dengan panas 2020-2050 derajat celcius.

\section{Pencetakan}

Setelah aluminium baru dan bekas dileburkan sampai meleleh maka akan dicetak ke dalam cetakan tanah liat atau cetak pasir yang membentuk panci atau wajan.

\section{Seleksi Hasil Pencetakan}

Tahap selanjutnya adalah proses seleksi karena setelah aluminium dicetak maka ada beberapa barang yang tidak terentuk sempurna, seperti ada lubang titik jarum, 
Vol. 10, No. 1 (Juni 2021)

Novitasari Eviyanti

DOI: http://dx.doi.org/10.26418/jaakfe.v10i1.45233

Hal 10-18

telinga/pegangan yang tidak terbentuk sempurna dan masih banyak lagi. Barang-barang yang tidak terbentuk sempurna ini akan diperbaiki, kalau sudah tidak bisa diperbaiki maka akan dikembalikan ke proses peleburan.

\section{Pengikiran dan pembubutan}

Peralatan yang lolos seleksi pencetakan maka akan masuk ke tahap pengikiran dan pembubutan, yaitu tahapan dimana peralatan tersebut diperhalus agar bisa digunakan.

\section{Seleksi Hasil Pembubutan}

Di tahapan ini akan dilakukan seleksi kembali dengan melihat apakah masih ada lubang atau bentuk yang tidak sempurna sesuai dengan standard yang telah ditentukan. Jika masih bisa diperbaiki maka akan diperbaiki ulang, jika tidak maka akan dikembalikan ke proses peleburan.

\section{Packing/ Poles}

Lalu barang yang lolos seleksi akan dipoles dan dipacking kemudian disimpan dan didistribusikan ke pelanggan.

\section{Analisis Biaya Kualitas Terhadap Penjualan}

Tabel 2 Analisis Biaya Kualitas terhadap Penjualan

\begin{tabular}{|l|l|l|l|l|l|}
\hline Tahun & $\begin{array}{l}\text { Prevention } \\
\text { Cost }\end{array}$ & $\begin{array}{l}\text { Appraisal } \\
\text { Cost }\end{array}$ & $\begin{array}{l}\text { Internal } \\
\text { Failure Cost }\end{array}$ & $\begin{array}{l}\text { External } \\
\text { Failure Cost }\end{array}$ & $\begin{array}{l}\text { Total Biaya } \\
\text { Kualitas }\end{array}$ \\
\hline 2014 & $1,38 \%$ & $2,33 \%$ & $13,57 \%$ & $0,61 \%$ & $17,88 \%$ \\
\hline 2015 & $1,43 \%$ & $2,29 \%$ & $14,47 \%$ & $0,65 \%$ & $18,85 \%$ \\
\hline 2016 & $1,58 \%$ & $2,35 \%$ & $14,86 \%$ & $0,59 \%$ & $19,38 \%$ \\
\hline 2017 & $1,57 \%$ & $2,28 \%$ & $14,05 \%$ & $0,57 \%$ & $18,47 \%$ \\
\hline 2018 & $1,79 \%$ & $2,36 \%$ & $14,05 \%$ & $0,57 \%$ & $17,68 \%$ \\
\hline
\end{tabular}

Sumber: Data diolah, 2018.

Dari data yang diolah diatas, dapat dilihat bahwa biaya kegagalan internal (internal failure cost) sangat tinggi jika dibandingkan yang lainnya, bahkan jauh diatas nilai yang ditetapkan oleh pakar kualitas dimana batas toleransi yang bisa diterima adalah 2,5\%. Biaya kegagalan internal tersebut tinggi dikarenakan SP Aluminium masih menggunakan perlatan tradisional untuk proses produksi dari awal hingga akhir sehingga masih banyak ditemukan produk cacat dalam proses produksi sehingga menyebabkan banyaknya waktu dan biaya yang terbuang.

"....disini memang alatnya masih manual dan tradisional semua mbak, mengingat para pekerja yang usianya sudah tua banyak, jadi kalau mau inovasi perlatan sama mesin takut tidak bisa mengikuti."(RI)

\section{Analisis Fishbone Diagram (Diagram Sebab Akibat)}

Berdasarkan hasil observasi dan wawancara yang dilakukan oleh peneliti, alur proses kegiatan produksi di SP Aluminium masih memiliki kekurangan sehingga masih banyak produk cacat yang dihasilkan. Mencari penyebab dari masalah yang dihadapi oleh SP Aluminium dapat 
Vol. 10, No. 1 (Juni 2021)

Novitasari Eviyanti

DOI: http://dx.doi.org/10.26418/jaakfe.v10i1.45233

Hal 10-18

diidentifikasi dengan fishbone diagaram dengan menelusuri proses produksi yang dilakukan oleh SP Aluminium dan membandingkan dengan proses bisnis perusahaan lain.

Beberapa unsur dari proses produksi SP Aluminium memiliki kendala diantaranya:

1. Manusia

a. Kurangnya pengetahuan

Dalam proses produksi, SP Aluminium memnggunakan $70 \%$ tenaga manusia dimana jika ada karyawan baru langsung diberikan tanggung jawab untuk mengerjakan produksi tanpa dibekali pelatihan terstruktur secara praktek dan teori untuk menunjang proses produksi. Karyawan baru ini juga tidak mengetahui mana bahan baku mana yang bagus ketika di produksi atau tidak.

"Untuk training kita tidak ada, hanya kalau ada karyawan baru langsung diterjunkan diberikan tanggung jawab satu pekerjaan atau satu ukuran produk, baru nanti kalau dilihat sekiranya bisa akan diberikan tanggung jawab yang lebih lagi. Contohnya ada 3 karyawan baru, dalam beberapa minggu akan kelihatan mana yang bisa lanjut atau tidak. Kalau ternyata tidak bisa lanjut dan ada bagian lain membutuhkan pegawai misal bagian packing maka akan diarahkan ke pekerjaan yang tidak begitu membutuhkan keterampilan." (BB)

b. Budaya

Melihat lokasi SP Aluminium yang berada di tengah masyarakat, membuat SP Aluminium tidak dapat lepas dari kebudayaan setempat. Produk yang tidak dapat tercapai dikarenakan banyaknya produk cacat yang dihasilkan selain itu juga karena pengaruh budaya di masyarakat. Para karyawan yang merupakan warga daerah sekitar tidak lepas dari budaya lingkungan, dimana ketika tetangga atau keluarga ada hajat maka akan libur semua proses produksi dikarenakan semua karyawan akan menghadiri/membantu hajat tersebut, bisa jadi libur produksi tiga sampai empat hari.

c. Tidak ada pelatihan berkala

SP Aluminium memiliki pelatihan untuk karyawan baru ataupun mitra, akan tetapi pelatihan tersebut tidak dilakukan setiap tahun atau setiap ada mitra baru yang bergabung. Pelatihan tersebut bisa dilakukan satu atau dua tahun sekali, padahal dalam jangka waktu tersebut tentunya banyak karyawan atau bahkan ada mitra yang bergabung.

d. Tidak memiliki keahlian khusus

Proses perekrutan karyawan hanya dilakukan dengan menerima warga sekitar yang membutuhkan pekerjaan sehingga dengan latar belakang yang bagaimanapun tentu akan diterima. Dengan demikian proses perekrutan tidak menentukan kualifikasi tertentu, asal mau bekerja pasti diterima.

2. Metode

Proses produksi SP Aluminium memiliki metode kikir, bubut dan poles yang masingmasing tahapan memilik quality control akan tetapi pada akhirnya tetap banyak produk cacat yang dihasilkan. Quality control yang dilakukan masih menggunakan tenaga manusia, sehingga kadang ada barang yang tidak sesuai namun tetap lolos ke proses selanjutnya, 
Vol. 10, No. 1 (Juni 2021)

Novitasari Eviyanti

DOI: http://dx.doi.org/10.26418/jaakfe.v10i1.45233

Hal 10-18

sehingga di akhir akan semakin banyak ditemukan produk cacat. Produk yang tidak sesuai di setiap tahapan akan dikembalikan ke proses awal, dimana jika bisa diperbaiki akan diperbaiki dan jika tidak bisa maka akan dilebur kembali.

3. Material

Dalam proses produksi SP Aluminium, aluminium batangan adalah bahan baku utama yang harus ada. Pengendalian dimulai ketika barang datang dari pemasok yang berupa aluminium batang dan aluminium rongsok. Aluminium batang harus dicek terlebih dahulu, apakah kadar yang ada sesuai dengan apa yang dibutuhkan sesuai dengan surat pre-order atau tidak dan mengecek aluminium rongsok apakah tidak ada campuran material lain seperti besi, tembaga atau material lain. Jadi para karyawan juga harus memisahkan kembali bahan baku rongsok jika tercampur dengan material lain.

4. Peralatan Produksi

Proses produksi memang tidak sepenuhnya menggunakan peralataran tradisional, ada beberapa tahapan yang menggunakan mesin yaitu proses pengikiran dan pembubutan dimana alatnya dibuat sendiri. SP Aluminium membuat peralatan sendiri sesuai dengan permintaan pelanggan yang biasanya untuk restoran-restoran besar.

Dalam pembuatan mesin dibutuhkan biaya yang tinggi untuk menentukan ukuran yang presisi, akan tetapi penggunaan mesin yang terus menerus akan mengakibatkan kerusakan dalam mesin prosuksi. Namun, untuk proses peleburan dan pencetakan masih menggunakan alat tradisional dimana banyak terdapat peralatan yang memiliki lubang jarum dan produk mati (tidak bisa diperbaiki), padahal peralatan tradisional yang berasal dari tanah liat ini memiliki waktu penggunaan maksimal empat hari, sehingga perusahaan harus mengeluarkan waktu dan biaya yang lebih untuk pembuatan peralatan cetak tradisional.

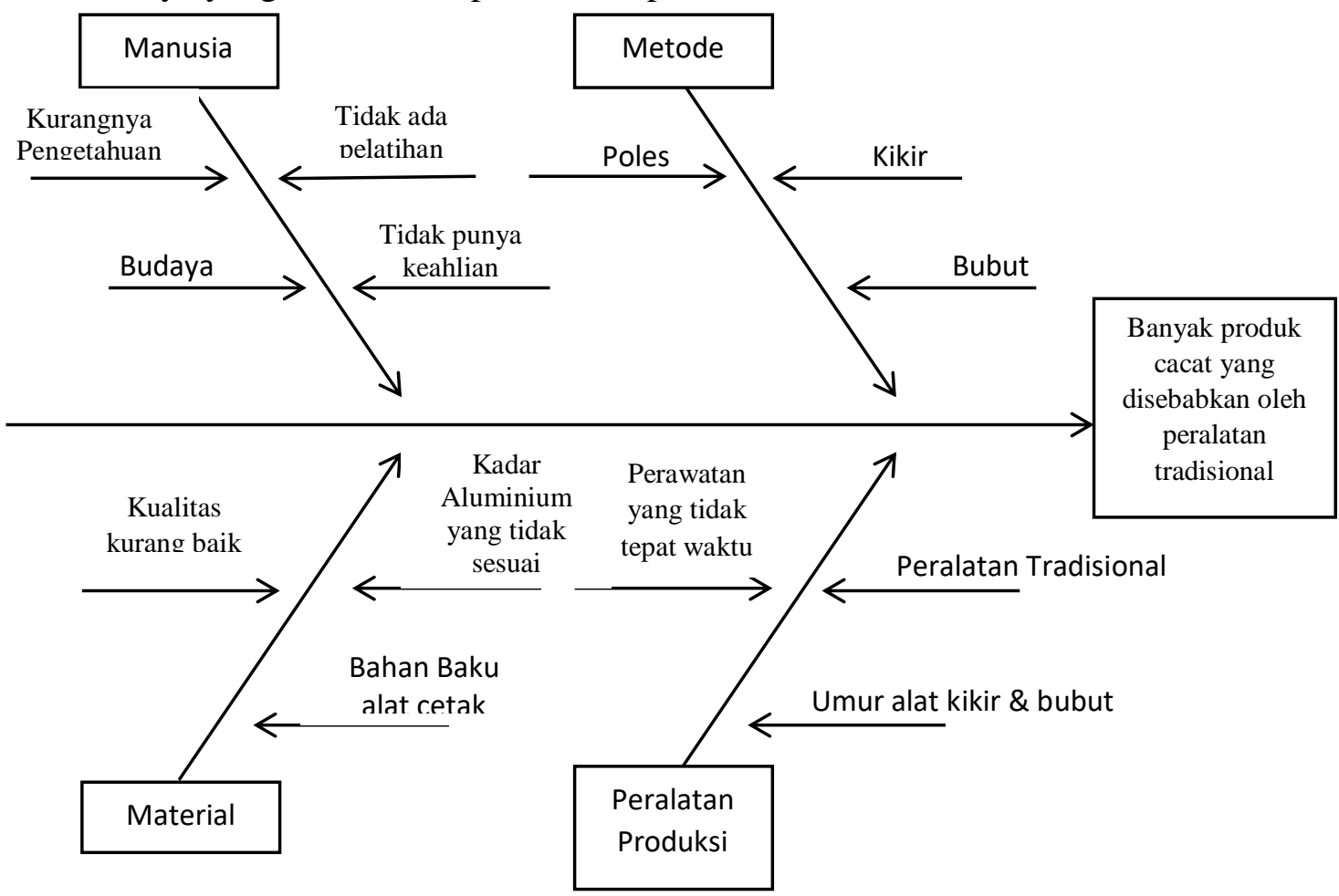


Vol. 10, No. 1 (Juni 2021)

Novitasari Eviyanti

DOI: http://dx.doi.org/10.26418/jaakfe.v10i1.45233

Hal 10-18

\section{KESIMPULAN DAN SARAN \\ Kesimpulan dan Saran}

Hambatan yang dialami oleh SP Aluminium dalam memenuhi permintaan pasar adalah di dalam proses produksi yang harus dibenahi agar meminimalisir biaya, waktu dan meningkatkan hasil produksi sehingga hasil akhirnya adalah untuk mengurangi biaya pengerjaan kembali produk cacat dan mememenuhi permintaan pasar hingga 100\%. Hambatan yang dihadapi oleh SP Aluminium ada beberapa factor seperti manusia yang disebabkan oleh kurangnya pengetahuan karyawan yang dikarenakan tidak adanya pelatihan terstruktur, dalam menerima karyawan tidak memandang latar belakang keahlian dan banyaknya waktu libur karena banyaknya acara di daerah lingkungan tersebut. Faktor metode yang digunakan seperti poles, kikir dan bubut masih menggunakan peralatan yang tradisional dan banyak produk yang tidak sesuai namun lolos quality control. Factor material dimana bahan baku alat cetak masih berupa tanah liat dan pasir yang umur penggunaannya maksimal hanya empat hari, kualitas dan kadar bahan baku yang kurang baik. Yang paling utama adalah di peralatan produksi yang masih tradisional, beberapa competitor dan UPT sudah menggunakan mesin automatisasi sehingga meminimalisir produk cacat, biaya, waktu dan tenaga kerja sehingga target produksi harian bisa tercapai.

\section{Saran}

Untuk peneliti selanjutnya, sebaiknya memperhitungkan biaya produksi dan pengadaan mesin sebagai pertimbangan SP Aluminium untuk mengadakan peralatan yang lebih modern dan meningkatkan efisiensi.

\section{DAFTAR PUSTAKA}

Besterfield, Dale H. 2004. Quality Control.7th Edition. Pearson Prentice Hall: New Jersey.

Carter, W. K dan Milton F, Usry. 2009. Akuntansi Biaya, Jilid 1 Edisi 14. Jakarta: Salemba Empat.

Cooper, Donald R, dan Pamela S. Schindler, 2006. Metode Riset Bisnis. Jakarta: PT Media Global Edukasi.

Gaspersz, Vincent. 2001. Total Quality Management. Jakarta: PT. Gramedia Pustaka Umum.

Hansen, Don R dan Maryanne M. Mowen. 2007. Managerial Accounting, 8th Edition. USA: Thomson South-Western.

Hennink, M., Hutter, I., dan Bailey, A. 2011. Qualitative Research Methods. London: Sage Publications

Kaplan, Robert S. and Robin Cooper. Cost \& Effect: Using Integrated Cost System to Drive Profitability and Performance. Boston, Massachusetts: Harvard Business School Press, 1998.

Kosasih. Sobarsa. 2009. Manajemen Operasi. Jakarta: Mitra Wacana Media.

Kotler, Philip. 2007. Manajemen Pemasaran. Jilid 2. Edisi 12. PT Indeks. New Jersey. 
Vol. 10, No. 1 (Juni 2021)

Novitasari Eviyanti

DOI: http://dx.doi.org/10.26418/jaakfe.v10i1.45233

Hal 10-18

Liliana, Luca. (2016). A New Model of Ishikawa Diagram for uality Assessment. Materials Science and Engineering. IOP Publishing

Sugiyono. 2014. Metode Penelitian Kuantitatif, Kualitatif, dan R\&D. Bandung: Alfabeta.

Supriyono, R.A. 2002. Akuntansi Biaya dan Akuntansi Manajemen untuk Teknologi Maju dan Globalisasi (Edisi Kedua). Yogyakarta: BPFE.

Yin, R. K. 2015. Studi Kasus (Desain dan Metode). Jakarta: PT. Raja Grafindo Persada. 